\title{
Ares I Aerodynamic Testing at the Boeing Polysonic Wind Tunnel*
}

\author{
Jeremy T. Pinier ${ }^{\dagger}$, \\ NASA Langley Research Center, Hampton, VA, 23681-2199 \\ Charles J. Niskey ${ }^{\ddagger}$ \\ Black Ram Engineering, Hampton, VA \\ Jeremy L. Hanke ${ }^{\S}$, and William G. Tomek ${ }^{\dagger}$ \\ NASA Langley Research Center, Hampton, VA, 23681-2199
}

\section{Notice to Reviewers}

The Ares I launch vehicle, including its predicted performance and certain other features and characteristics, have been defined by the U.S. Government to be Sensitive But Unclassified (SBU). Information deemed to be SBU requires special protection and may not be disclosed to an international audience, such as the audience sure to be present at the 2011 Aerospace Sciences Meeting. To comply with SBU restrictions, details have been removed from some plots and figures in this abstract. It is the opinion of the authors that despite these alterations, there is no loss of meaningful technical content. Analytical methodologies and capabilities are discussed; significant and interesting technical results are obvious and still present; and meaningful conclusions are still present.

Throughout three full design analysis cycles, the Ares I project within the Constellation program has consistently relied on the Boeing Polysonic Wind Tunnel (PSWT) for aerodynamic testing of the subsonic, transonic and supersonic portions of the atmospheric flight envelope (Mach=0.5 to 4.5). Each design cycle required the development of aerodynamic databases for the 6 degree-of-freedom (DOF) forces and moments, as well as distributed line-loads databases covering the full range of Mach number, total angle-of-attack, and aerodynamic roll angle. The high fidelity data collected in this facility has been consistent with the data collected in NASA Langley's Unitary Plan Wind Tunnel (UPWT) at the overlapping condition of Mach=1.6. Much insight into the aerodynamic behavior of the launch vehicle during all phases of flight was gained through wind tunnel testing. Important knowledge pertaining to slender launch vehicle aerodynamics in particular was accumulated. In conducting these wind tunnel tests and developing experimental aerodynamic databases, some challenges were encountered and are reported as lessons learned in this paper for the benefit of future crew launch vehicle aerodynamic developments.

\section{Nomenclature}

\section{Symbols}

$\alpha \quad$ Pitch angle, deg

$\phi \quad$ Roll angle, deg

$C_{p} \quad$ Pressure coefficient

$D \quad$ Reference diameter, $i n$.

$L \quad$ Length of vehicle, model scale

$L_{r e f} \quad$ Reference length, $i n$.

$M \quad$ Mach number

$p \quad$ Pressure, $l b /$ in $^{2}$

$p_{o} \quad$ Freestream static pressure, $l b / \mathrm{in}^{2}$

$q \quad$ Freestream dynamic pressure, $l b / f t^{2}$

Re Reynolds number, / ft

$x \quad$ distance along model centerline, zero at tip of the LAS tower, $i n$.

* Submitted to the ARES special session.

${ }^{\dagger}$ Research Aerospace Engineer, Configuration Aerodynamics Branch, MS 499, Senior Member AIAA.

$¥$ Aerospace Engineer, Black Ram Engineering, Senior Member AIAA.

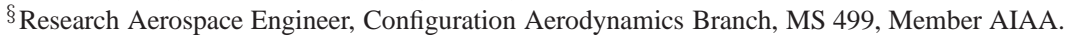




\section{Acronyms}

$\begin{array}{ll}\text { AMS } & \text { angle measurement system } \\ \text { ADAC } & \text { alternate design analysis cycle } \\ \text { BDM } & \text { booster decelerator motor } \\ \text { BMC } & \text { balance moment center } \\ \text { CFD } & \text { computational fluid dynamics } \\ \text { CLV } & \text { crew launch vehicle } \\ \text { DAC } & \text { design analysis cycle } \\ \text { DOF } & \text { degrees of freedom } \\ \text { ESP } & \text { electronically scanned pressure } \\ \text { FS } & \text { first stage } \\ \text { GNC } & \text { guidance, navigation and control } \\ \text { LAS } & \text { launch abort system } \\ \text { OML } & \text { outer mold line } \\ \text { PDR } & \text { preliminary design review } \\ \text { RCS } & \text { reaction control system } \\ \text { RoCS } & \text { roll control system } \\ \text { US } & \text { upper stage }\end{array}$

\section{Introduction}

Wind tunnel testing has been the primary source of integrated aerodynamic forces and moments for high-fidelity databases within the Constellation program. Computational fluid dynamics (CFD) simulations were calibrated against wind tunnel data during the early design analysis cycles (DAC) to enable the development of incremental databases during subsequent design cycles where it is impractical or unfeasible to test in a wind tunnel. As an example, constructing a line-loads database from experimental data would require building a model with thousands of surface pressure measurements, which is not an option at the scales at which tests were performed. After validation of the computed surface pressure with a more sparse distribution of pressure sensors, CFD results could be used to provide a fine resolution line-loads database. On the other hand, integrated aerodynamic force and moment measurements, using internal strain gage balances, are consistently performed in wind tunnels as they provide a large number of data points for a high-fidelity database. This combination of wind tunnel tests and calibrated CFD analysis enabled the development of all aerodynamic databases for the Ares I launch vehicle from lift-off to stage separation and first stage reentry for use by the guidance navigation and control (GNC), flight mechanics and structures teams. This paper presents the techniques and instrumentation involved in testing pressure and integrated forces and moment models at the Boeing Polysonic Wind Tunnel. Additionally, a selection of results and analysis methods are presented, and lessons learned relating to wind tunnel testing of this type of slender launch vehicles are presented.

\section{A. The Ares I Crew Launch Vehicle}

Ares I is an in-line, two-stage, crew launch vehicle, with a solid rocket booster (SRB) first stage inherited from the space shuttle boosters and modified with an added fifth segment. The upper stage is a $\mathrm{LOX} / \mathrm{LH}_{2}$ motor with a Saturn derived J2-X engine. Figure 1 shows the outer mold line (OML) of the full stack Ares I vehicle in its second design cycle configuration. A striking feature of this launch vehicle is its slenderness. This typically presents wind tunnel testing challenges. The length of the vehicle along with the typical test section sizes at transonic and low supersonic Mach numbers limits the scale at which the model can be tested. At transonic Mach numbers, shocks and expansion wave angles are steep and their reflection on the test section walls and back onto the model are always a concern. This effect was investigated during both pressure and integrated loads tests during which it was found that the effects are much more subtle on this type of vehicle than on airplane-type configurations with significant lifting surfaces. The shock reflection issue is discussed in more detail in the third section of this paper. The slenderness of the vehicle also results in a constraint on the amount of instrumentation that can be embedded within the wind tunnel models. 


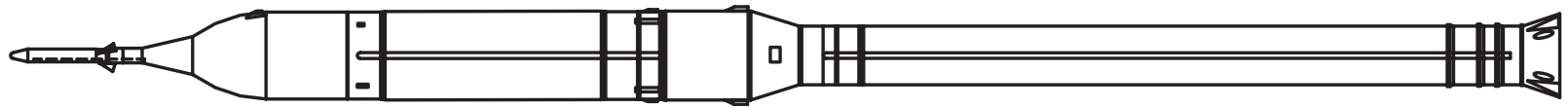

ADAC-2B (A103) Top View

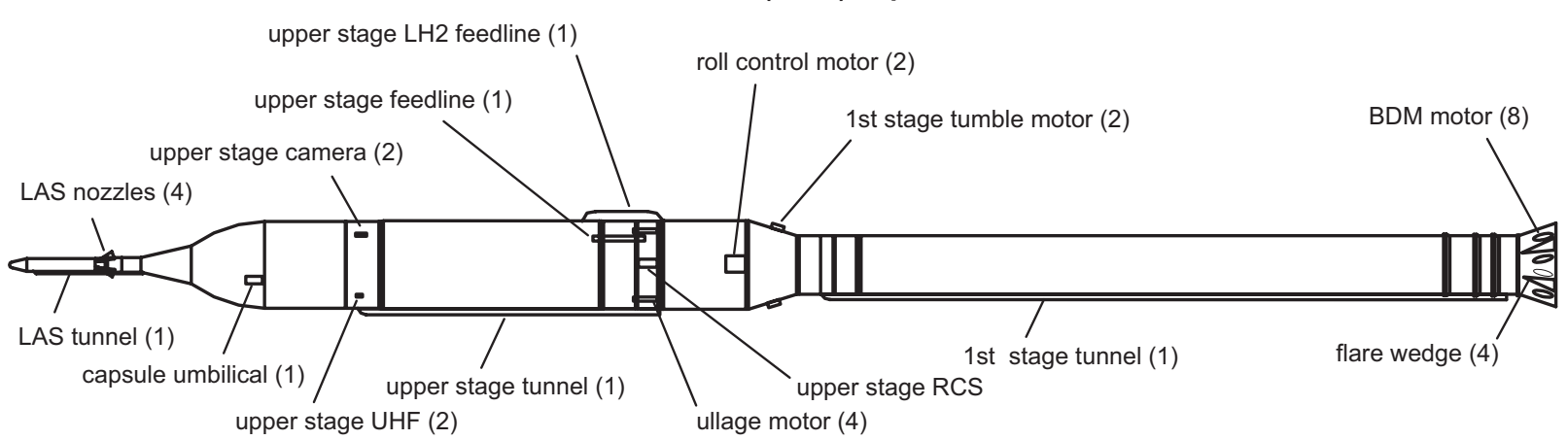

Figure 1. Side and top views of the Ares I (A103) launch vehicle with description of outer mold line protuberances, drawing not to scale.

\section{B. The Boeing Polysonic Wind Tunnel}
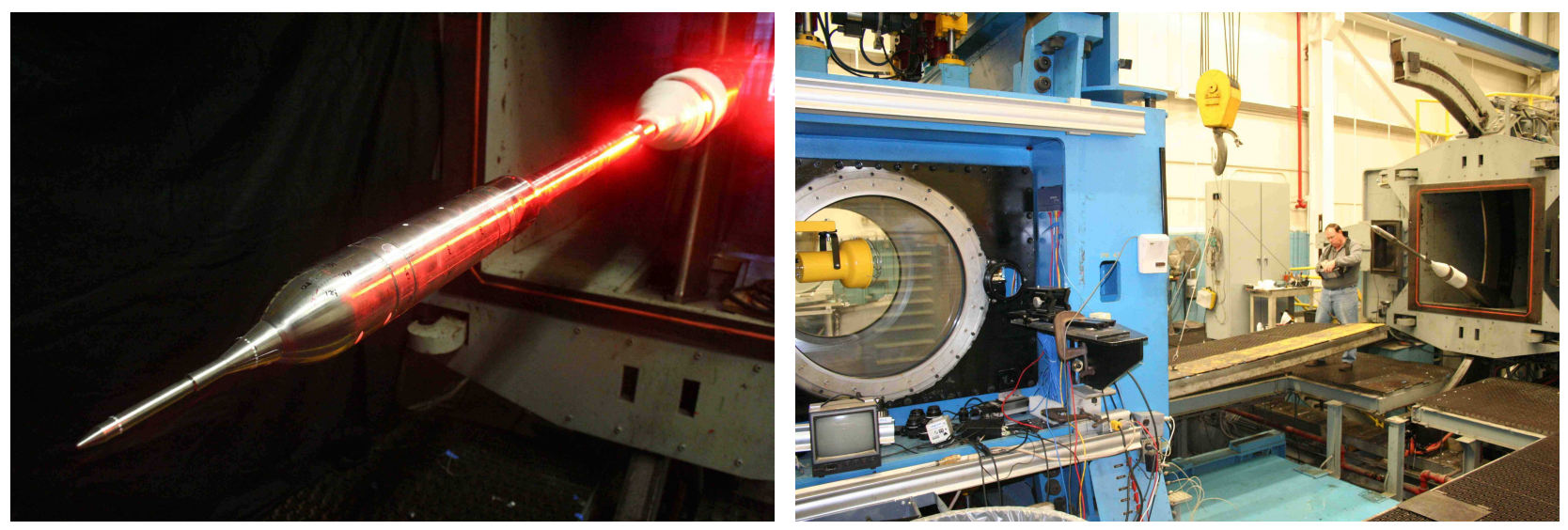

Figure 2. Ares I CLV ADAC-2B (A103) model (left) and Boeing PSWT supersonic test section (right).

The Boeing Polysonic Wind Tunnel (PSWT) in St Louis, Missouri, is an in-line blow-down tunnel with a square $4 \times 4$ foot test section that uses a removable transonic test section cart to operate from $M=0.45$ to 1.6. The cart is removed for testing in the higher supersonic range from $M=1.6$ to 5.5. During testing, steady force-and-moment data was acquired over the lower Mach range (transonic test section) and pressure data was acquired over the entire Mach range (transonic and supersonic test sections). Figure 2 shows a picture of the open facility with the transonic cart removed and an Ares I model mounted on the sting and arc sector support system. The facility operates mainly on a large gas turbine compressor that pumps air at a rate of $30 \mathrm{lb} / \mathrm{s}$ and a second back-up electric compressor can be brought online to provide an additional $15 \mathrm{lb} / \mathrm{s}$, which proves useful to increase productivity. During subsonic and transonic operations $(0.5<M<1.6)$ the removable transonic test section with perforated side walls is used to provide boundary layer suction, minimize shock and expansion wave reflections as well as wall interferences and provide a co-flow for easier start-up of the tunnel. Additionally, downstream ejectors provide the low pressure needed to start the tunnel without overloading the test article in the test section. Automatic control of plenum pressure as well as throttled flaps located in the diffuser allow for active control of Mach number. During supersonic operations $(1.6<M<4.5)$, the transonic test section is removed to provide a solid wall test section and a flexible plate nozzle allows adjustment of the throat area to control Mach number. In this mode, the start and un-start loads on the test article are much higher. Due to the small size of the model and the expected aerodynamic loads, relatively small 
balances were used (typically $30 \mathrm{lbs}$ on axial force). The use of this wind tunnel for supersonic Mach numbers was therefore limited due to excessive start and un-start loads. A continuous flow wind tunnel, such as NASA Langley's Unitary Plan Wind Tunnel (UPWT), was used for integrated loads testing at $1.6<M<4.5$. The design of pressure instrumented models does not require strain gauge balance measurements and can allow for a larger diameter sting that withstands the high tunnel start loads. Therefore, pressure tests were performed over the entire Mach range at the PSWT. Since the wind tunnel is a blow-down open circuit tunnel, between 20 and 50 seconds of data can be acquired in one blow-down cycle, depending on the conditions. Data acquisition during pitch and roll polars is therefore performed continuously for efficiency (as opposed to pausing the model at each attitude where data is required) and low-pass filtering is applied to the data to eliminate the fluctuations due to small oscillations of the model in the flow. The continuous pitch/roll sweep technique can present challenges when running at low static pressures, in which case, pressure lags can occur in long tubes and therefore measurements can be corrupted. Special care needs to be taken when designing the pressure instrumentation and running continuous sweeps to ensure that there will not be any lag in the measurements. More about this challenge is discussed in Section V. B.

One additional feature pertaining to this facility is its ability to perform Mach sweeps in the subsonic/transonic mode by actively controlling the main valve opening during the blow-down cycle. It was thus possible to acquire data during Mach sweeps from around $M=0.7$ to 1.15. Mach polars are beneficial in identifying the potential effects of shock reflections occurring throughout this regime. Results from such an investigation will be discussed in the lessons learned section of the paper.

\section{Force and Moment Testing}

As previously mentioned, the flow regime tested at the Boeing PSWT during force and moment tests was from $M=0.5$ to 1.6. The higher Mach number testing was performed in NASA Langley's UPWT and results from Ares I wind tunnel tests in that facility can be found in Erickson et al ${ }^{1}$. The wind tunnel reports by Hanke ${ }^{2}$ and Pinier ${ }^{3}$ describe in detail two force and moment tests performed at the Polysonic Wind Tunnel.

\section{A. Model description}

DAC-1 Side View

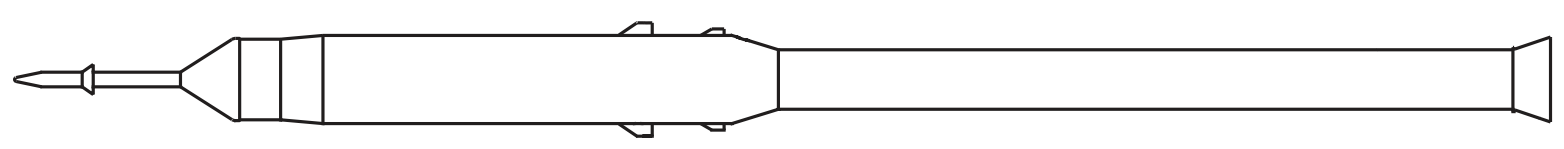

ADAC-2A (A101) Side View

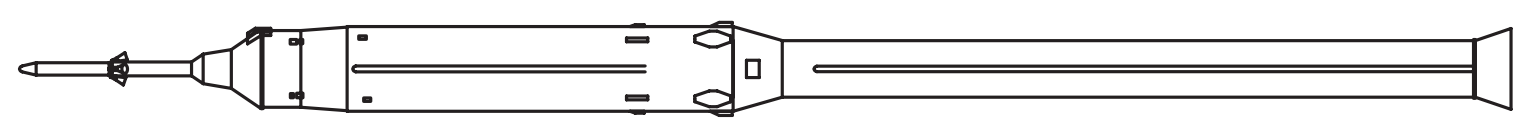

ADAC-2B (A103) Side View

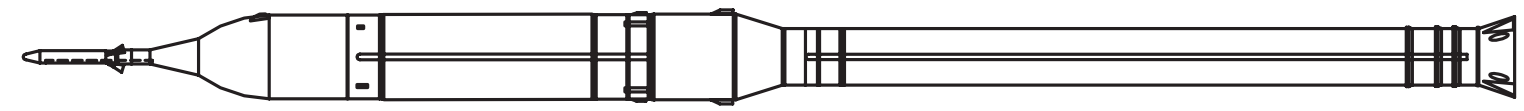

Figure 3. Side views of the main Ares I configurations tested at PSWT, with DAC-1 (top), ADAC-2A (A101) (middle) and ADAC-2B (A103) (bottom), drawings not to scale.

Figure 3 shows the successive changes in the OML as the design went through analysis cycles. The first config- 
uration tested was the CLV Rev 4.1, very similar to DAC-1, characterized by a conical crew module fairing. Two DAC-1 models were built and tested at PSWT: a pressure model and a force and moment model. During the second design cycle, a force and moment model for an initial design (ADAC-2A (A101)) was built and tested with a slightly modified crew module fairing. Then, a second design (ADAC-2B (A103)), with the most striking difference being the tangential-ogive shaped crew module fairing was built and tested. Both a pressure and a force and moment model were built for this configuration. The latest model tested was part of the third design cycle but has only small modifications to the previous ADAC-2B configuration, most of the differences being in the placement and geometry of the multiple protuberances. This most recent configuration tested was designated as ADAC-3 (A106).

All models tested at this facility were $1 \%$ of full scale size for a total length on the order of 40 inches and the diameter of the first stage was used as a reference length measuring on the order of $1.5 \mathrm{inch}$. This scale was large enough to be able to manufacture the small protuberances on the outside of the model, while small enough to get quality data in a 4-foot test section wind tunnel, minimizing the Mach range where shock reflection on the model can be a concern.

All the external protuberances were removable except for any axisymmetric stiffener ring or local diameter change to enable testing of a 'clean' configuration (i.e. axisymmetric, no protuberances installed). Testing of the clean configuration was performed to measure any bias due to geometry imperfections and any misalignment between the support system, sting, balance, model, and flow that remained unaccounted for during installation in the tunnel. Any measurable bias was removed from the full protuberance configuration data during post-processing to reduce the experimental uncertainties.

The models were primarily built from aluminum to limit the weight and therefore minimize the oscillations and vibrations when subject to the flow. Stainless steel was used for the high-precision parts including the balance block, by which the model is fastened to the balance.

The unit Reynolds number on a $1 \%$-scale model is around $6 \times 10^{6} / \mathrm{ft}$, or two orders of magnitude below flight Reynolds number during some phases of flight. The boundary layer therefore needed to be tripped to ensure transition to turbulence and a closer representation of the flight Reynolds number flow. However, slender bodies of revolution that are rolled during testing present a real challenge with respect to the placement of the transition grit or trip dots. After an investigation into that matter ${ }^{4}$ using various transition grit patterns and qualitative diagnostic techniques such as sublimation, it was concluded that several circumferential trip dot strips with heights tailored to the Mach number range and applied to the upper portion of the model near the launch abort system tower would be sufficient to force transition to turbulence on the surface of the vehicle. However this topic remains an open one and deserves further in-depth investigations if transition to turbulence shows up as a large factor in the measurement uncertainties. None of the data collected thus far has shown significant sensitivity to the boundary layer tripping strategy.

\section{B. Instrumentation}

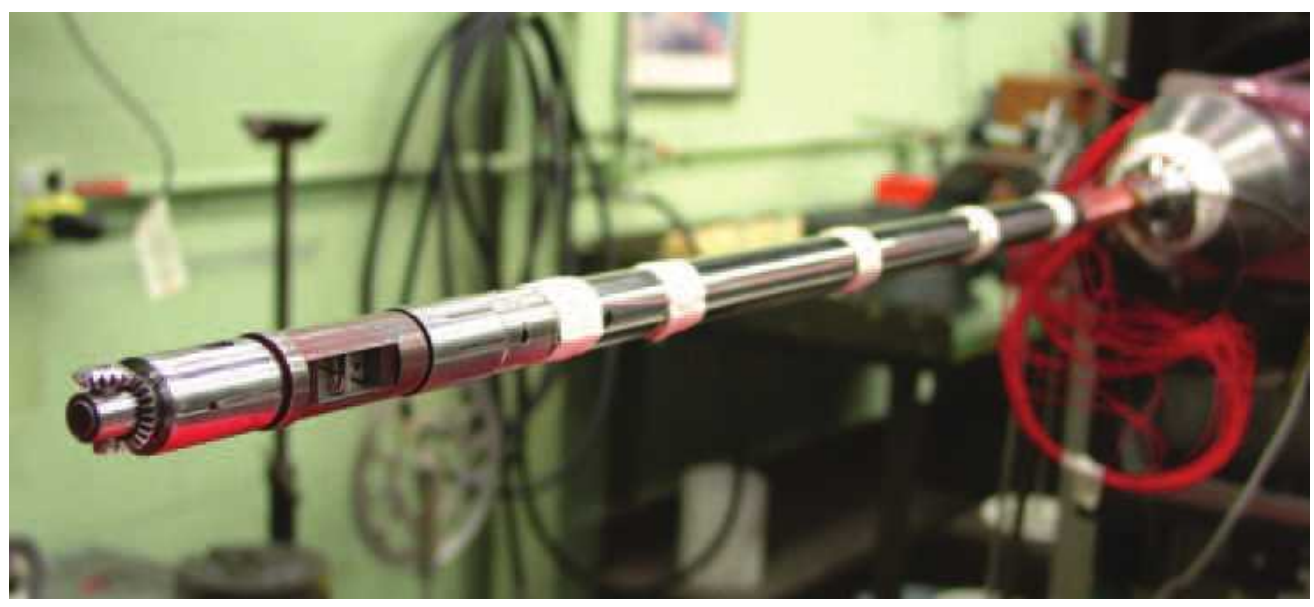

Figure 4. Internal strain-gauge balance used during the wind tunnel tests at PSWT.

The models were mounted on 6-component internal strain gage balances, with the balance moment center (BMC) approximately placed around the estimated center of pressure location, near the frustum area of the model (the diame- 
ter change area between the first stage and the interstage). The balance itself was mounted on a slender stainless steel (Vascomax) sting, which results in a limber and flexible setup. Figure 4 shows the UT 39-B balance facing forward mounted on the UPWT 350-25A sting. The balances used were recently-calibrated direct-read Langley balances and were chosen to fit the expected loads during testing. The model is a rather slender launch vehicle without lifting surfaces so rolling moment was expected to be small. The measured rolling moments during the tests still were small relative to the full-scale allowable load for these balances. Only a small part of the calibrated range of the balance was utilized, which partly explains the higher uncertainties experienced in the rolling moment results. More details on this topic are discussed in Section V. Best practices related to the calibration and use of internal strain gage balances as described by the AIAA Recommended Practices ${ }^{5}$ were followed during Ares I testing.

A total of six pressure tubes were run along the sting to measure the base pressure and the cavity pressure inside the back end of the model. Electronically scanned pressure (ESP) modules were used as well as Kulite sensors to perform these measurements. Both showed to be comparatively reliable over the course of the tests. These six measurements are averaged and multiplied by the base surface area to provide a base drag that is subtracted from axial force to provide fore-body forces.

In case the aft-end of the model made contact with the sting (fouling), a fouling strip was installed to trigger a binary output and indicate compromised data. Overall, only very local fouling was observed in the supersonic test section at relatively high angles-of-attack ( $\alpha=8-10$ degrees), where significant lateral as well as longitudinal dynamics were observed. In any instance where fouling was observed, the data was discarded at and around these data points.

The model/balance/sting assembly was mounted to the tunnel's support system which consists of a 360-degree roll-coupler and an arc-sector in the pitch plane with a center of rotation on the tunnel centerline around mid-length of the model to enabled pitching of the model covering the requirement of -10 to +10 degrees angle-of-attack, while remaining in the center of the test section for optimal flow quality.
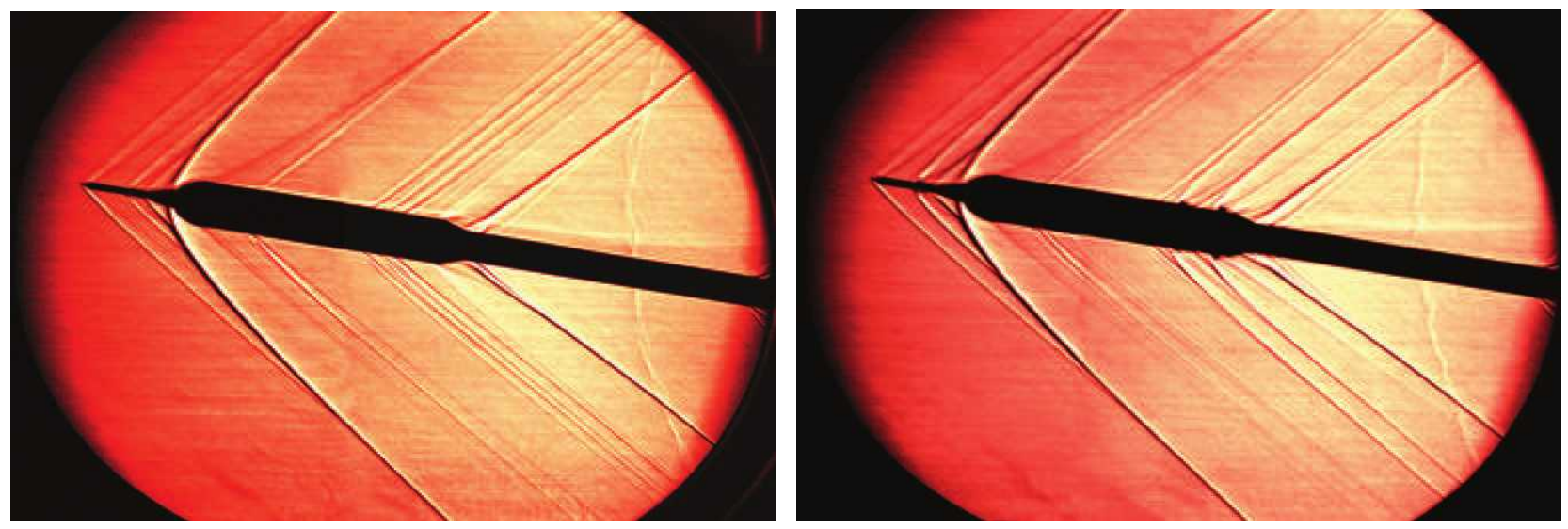

Figure 5. Ares I CLV ADAC-3 (A106) force and moment model, clean (left) and full protuberance (right) configurations.

Schlieren flow visualization was utilized during the supersonic portion of testing where optical access was available. High-resolution images provide insight into the shock interactions and shock angles, as well as some information relating to the potential reflection back onto the model and corruption of the data in the low-supersonic portion of testing. Figure 5 shows Schlieren visualizations of the CLV at $10^{\circ}$ angle-of-attack at a Mach number of 1.6.

\section{Pressure Tests}

The wind tunnel test report by Pinier $^{6}$ describes in detail the latest pressure test performed at the PSWT. 


\section{A. Model description}

Two separate $1 \%$-scale pressure tests were conducted in this wind tunnel. The first one was completed early-on during the first design cycle and the model only contained one longitudinal row of 100 static surface pressure taps along the top length of the model. The second test was completed during the second design analysis cycle and this time employed 199 pressure taps. In addition to 115 taps along the top longitudinal surface, another 84 taps were spread around the various protuberances to compare to CFD simulations. The second more comprehensive test is discussed in this paper and a selection of results from this investigation are shown in Section IV.

\section{B. Instrumentation}

to complete the two main objectives of the pressure test, 199 static pressure ports were distributed on the vehicle surface:

- 115 pressure taps distributed along the top centerline (at $\phi=0^{\circ}$ ) from $\mathrm{x} / \mathrm{L}=0.065$ to $\mathrm{x} / \mathrm{L}=0.996$,

- 18 taps located around the capsule umbilical,

- 8 taps located upstream of the top centerline RCS,

- 46 taps located around the $\mathrm{LH}_{2}$ feed-line,

- 8 taps located around the upper stage system tunnel,

- 4 taps located at $\phi=180^{\circ}$ on the crew module area for flow angularity measurements.

The top centerline row of 115 pressure taps was designed to accomplish the first test objective: determine the lineloads distribution along the length of the body. Since the full protuberance configuration model is non-axisymmetric, the measurement of line-loads is impractical experimentally. Therefore line-loads can only be estimated on the clean (axisymmetric) configuration by taking measurements along the top row of taps at multiple discrete roll angles and integrating these results to compute the distributed line-loads. The normal and axial line-loads are computed respectively as follows:

$$
\begin{gathered}
\frac{d C_{N}(\hat{x})}{d \hat{x}}=\frac{4}{\pi} \hat{R}(\hat{x})\left[\int_{0}^{1} c_{p, l}(\hat{x}, \hat{y}) d \hat{y}-\int_{0}^{1} c_{p, u}(\hat{x}, \hat{y}) d \hat{y}\right] \\
\frac{d C_{A F}(\hat{x})}{d \hat{x}}=\frac{2}{\pi} \hat{R}(\hat{x}) \frac{d \hat{R}(\hat{x})}{d(\hat{x})} \int_{0}^{x} c_{p}(\hat{x}, \phi) d \phi
\end{gathered}
$$

where $C_{N}$ and $C_{A F}$ are the normal and axial force coefficients respectively; $\hat{x}, \hat{y}$ and $\hat{R}$ are the non-dimensional downstream location and spanwise distance respectively, $\hat{R}$ the local non-dimensional radius, $c_{p, u}$ and $c_{p, l}$ are the pressure coefficients on the upper $\left(\phi=0^{\circ}\right.$ to $\left.\phi=90^{\circ}\right)$ and lower $\left(\phi=90^{\circ}\right.$ to $\left.\phi=180^{\circ}\right)$ surface respectively. The remaining pressure taps were located around protuberances of interest to fulfill the second objective of the test. The umbilical, the RoCS, the $\mathrm{LH}_{2}$ feed-line fairing and the US tunnel were chosen as areas where the flow could present challenges for CFD simulations. Figure 6 shows surface pressure contours around the $\mathrm{LH}_{2}$ feed-line fairing. CFD was used to determine the location of the high surface pressure gradients and indicate optimal locations for the pressure taps around the protuberances. Stainless steel tubing with an outer diameter of $0.040 \mathrm{in}$. and inner diameter of $0.020 \mathrm{in}$. was inserted from inside the model and mounted flush with the outer surface of the model to ensure minimal disturbance to the flow around the measurement point. The 199-tube bundle extended out the aft end of the integrated sting. Clear urethane tubing was used to connect the stainless steel tubing to the 5 electronically scanned pressure (ESP) modules. These were located approximately two feet from the back of the sting in cavities within the arc sector roll pod. A layer of vibration-absorbing foam was used to isolate the measurement devices from tunnel vibrations. A calibration of the ESP modules was performed before each run. The pressure data was acquired at a sampling rate of $50 \mathrm{~Hz}$ and 2 seconds of data was acquired per point. The data was then digitally low-pass filtered at a cut-off frequency of $2 \mathrm{~Hz}$ and finally averaged over the 100 samples to result in the final data point. The manufacturer-specified accuracy of the ESP modules is $0.1 \%$ of full-scale, meaning in this case $+/-0.015$ psi. 


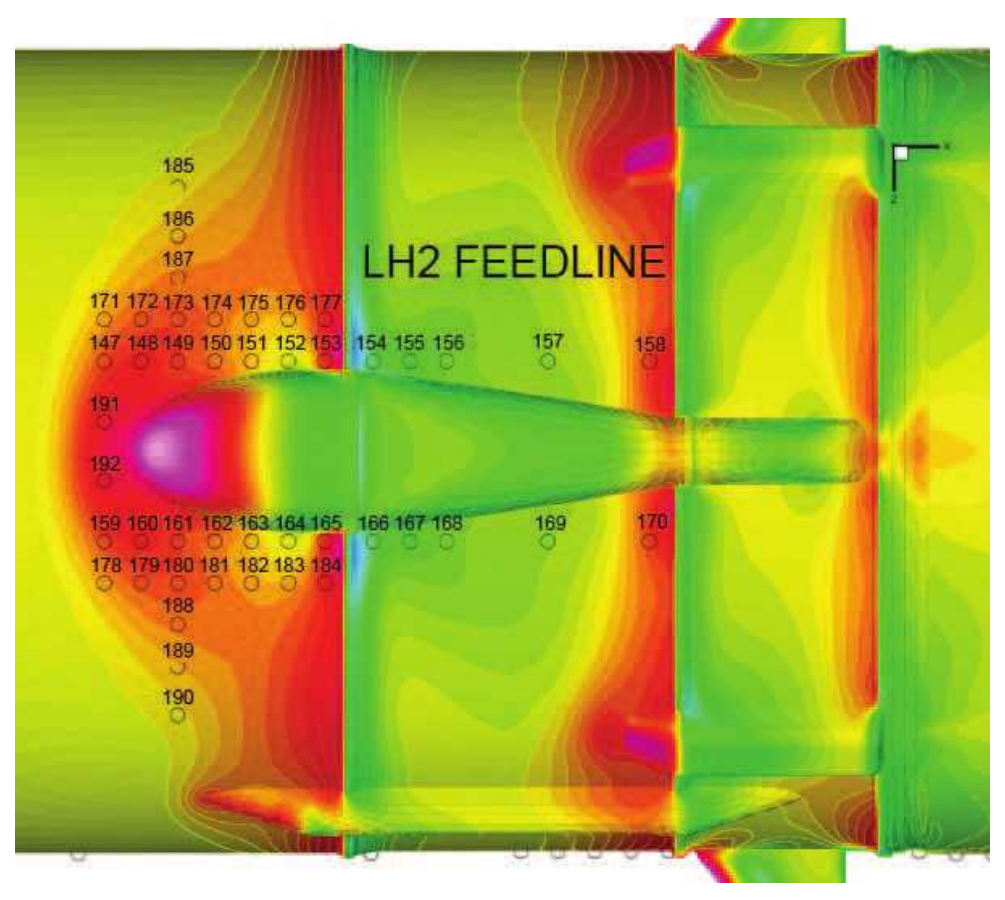

Figure 6. Layout of pressure taps around the $\mathrm{LH}_{2}$ feedline fairing, with surface pressure contours from CFD analysis.

\section{Results}

\section{A. Data repeatability}

Repeatability assessments were performed at regular intervals during the tests and were of two different types:

1. A reference set of runs was performed initially and then at regular intervals during the tests to ensure data consistency throughout the length of the tests. Any unexpected change in flow quality or any balance issue would be uncovered and investigated before any additional production runs were performed. Being a blowdown facility, the down time periods between each cycle are a convenient opportunity for mining the large amounts of data and ensuring that all measurements are nominal. Several critical issues were found during these reference runs, some of which are discussed in Section V.

2. Uncertainty assessment repeat runs were also performed throughout the test to capture the dependency of data repeatability with all the variables. During post-processing, statistical methods are used to quantify repeatability $^{7}$. It is therefore important to gather repeatability data at many attitudes and flow conditions to detect any correlation in the residuals, in which case an uncertainty model can be built using this information.

Figure 7 shows trends of the force and moment variations during two repeat pitch sweep runs covering negative to positive angles-of-attack. Since absolute magnitudes are not provided, the reader should focus on the relative magnitude of the measurement variation between repeats with respect to the full scale value. Naturally, the total variation of the longitudinal loads over the pitch sweep is greater than that of the lateral loads, the scales of which are magnified to show small variations. Also shown are the balance calibration uncertainties (or balance accuracy) in the form of error bars. These uncertainties are computed during the balance calibration in a controlled environment. Repeatability discrepancies from run to run in the tunnel is usually greater than the balance accuracy. However, it is noticed that rolling moment repeatability is better than the balance accuracy which is not uncommon for Langley-type balances.

Figure 8 shows the magnitude of the force and moment variations during 8 repeated roll sweep runs covering the entire 0 to 360 degree roll range. These repeat runs were spaced throughout the entire span of the test to check for consistent data quality throughout the test duration, as mentioned above. Naturally, the total variation of the lateral loads over the roll sweep is greater than that of the longitudinal loads, the scales of which are magnified to show small variations. These data show the very good quality and consistency of the the data set over an entire test campaign. Throughout the several integrated force and moment tests on the Ares I vehicle, rolling moment showed to be the most challenging quantity to measure. Indeed the typical rolling moments experienced by the $1 \%$ scale Ares I models 

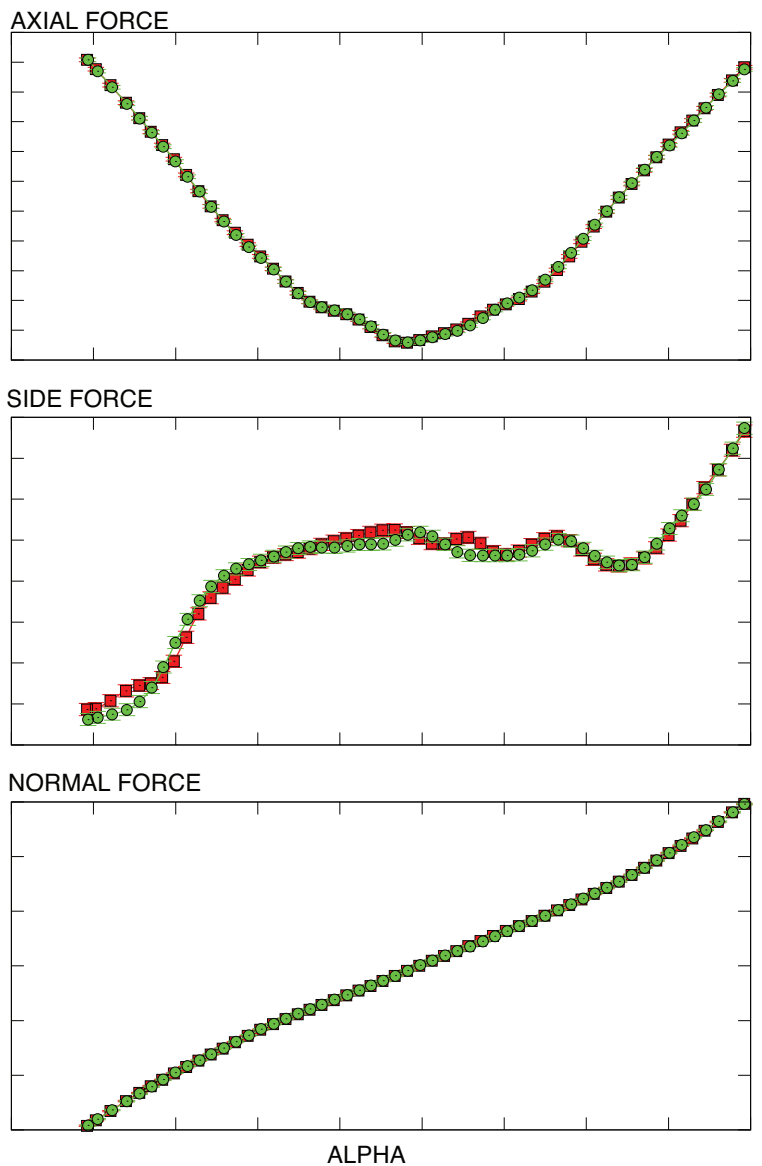
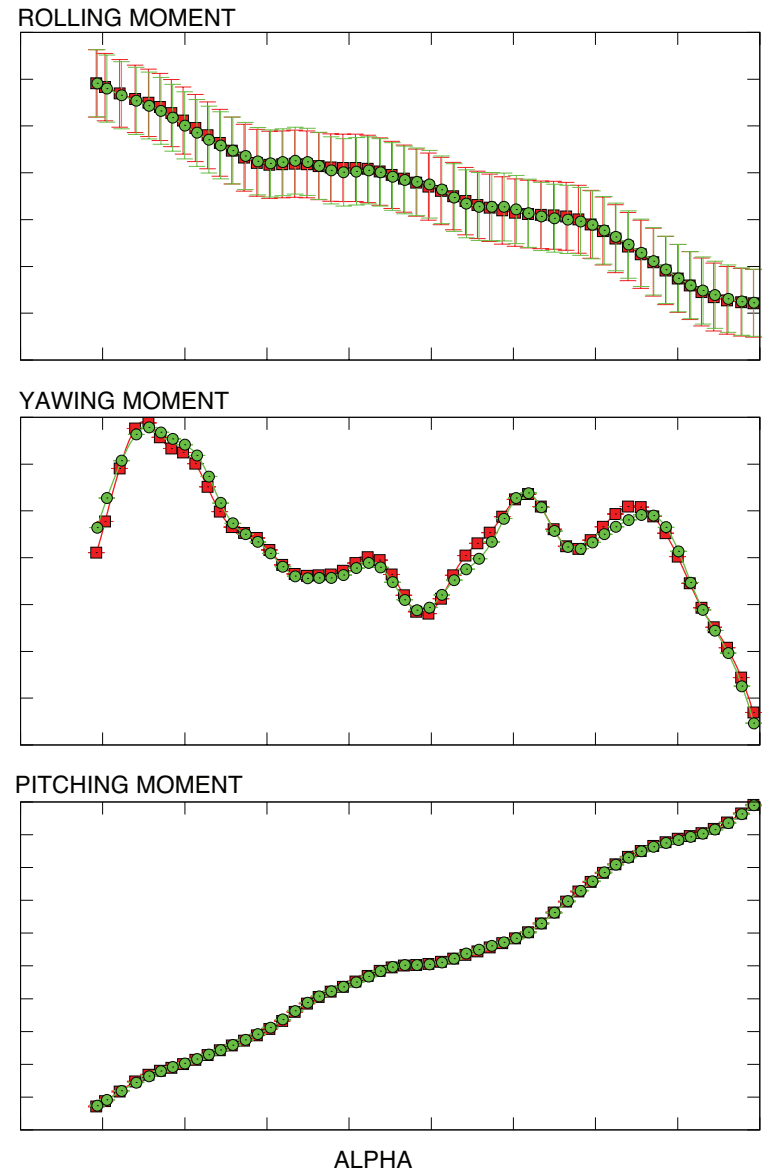

Figure 7. Force and moment repeatability during a low angle-of-attack pitch sweep at $M=1.61$. 

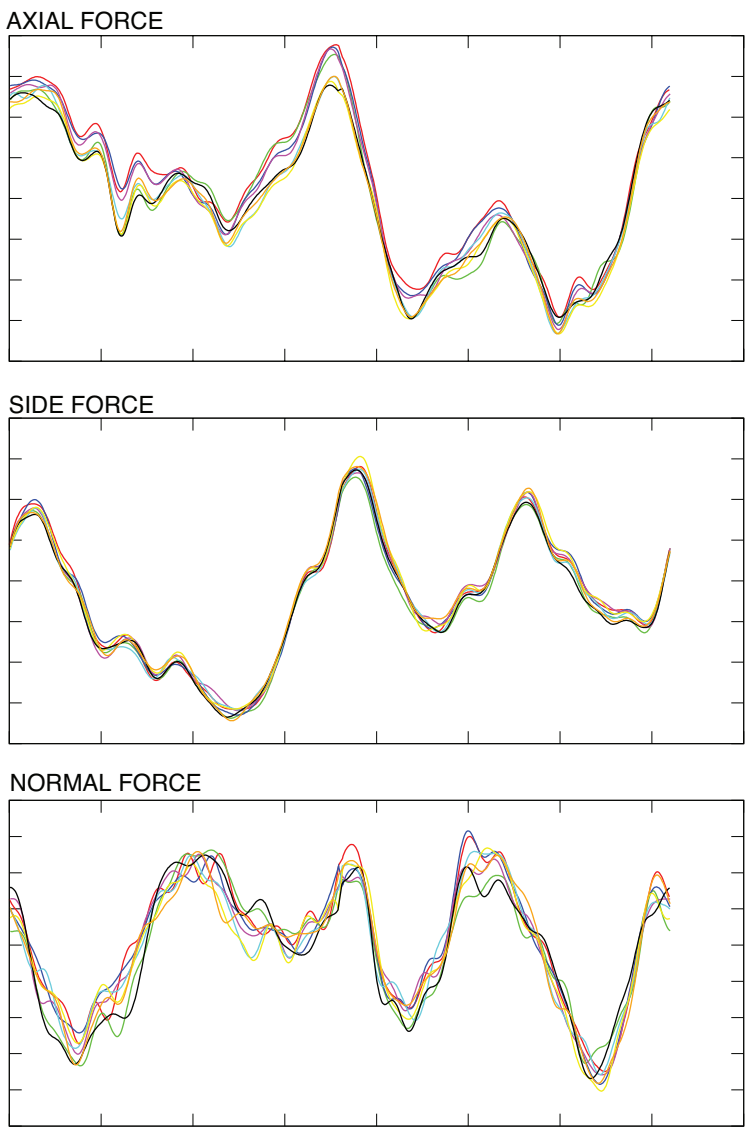

ROLL ANGLE

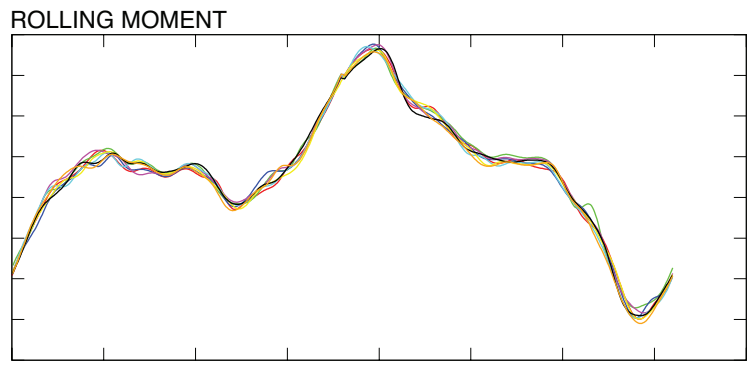

YAWING MOMENT

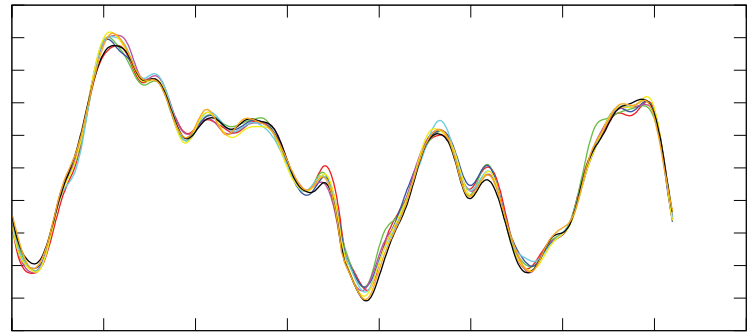

PITCHING MOMENT

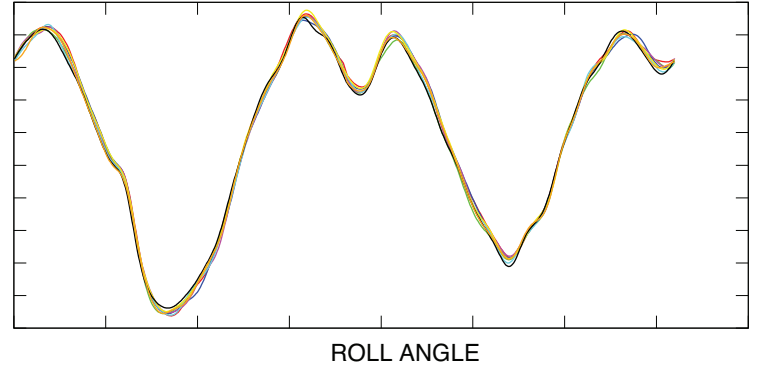

Figure 8. Force and moment repeatability during a low angle-of-attack roll sweep at M=1.61. 
peaked at the higher angles-of-attack at a maximum of 5\% of the full scale physical limit of the balance, thus reducing the accuracy of the measurement.

\section{B. Data plots}

\section{Integrated loads}

A set of typical aerodynamic forces and moments experienced by the vehicle at a selected number of conditions is presented in this section to show the types of trends that are characteristic of such launch vehicle aerodynamics.
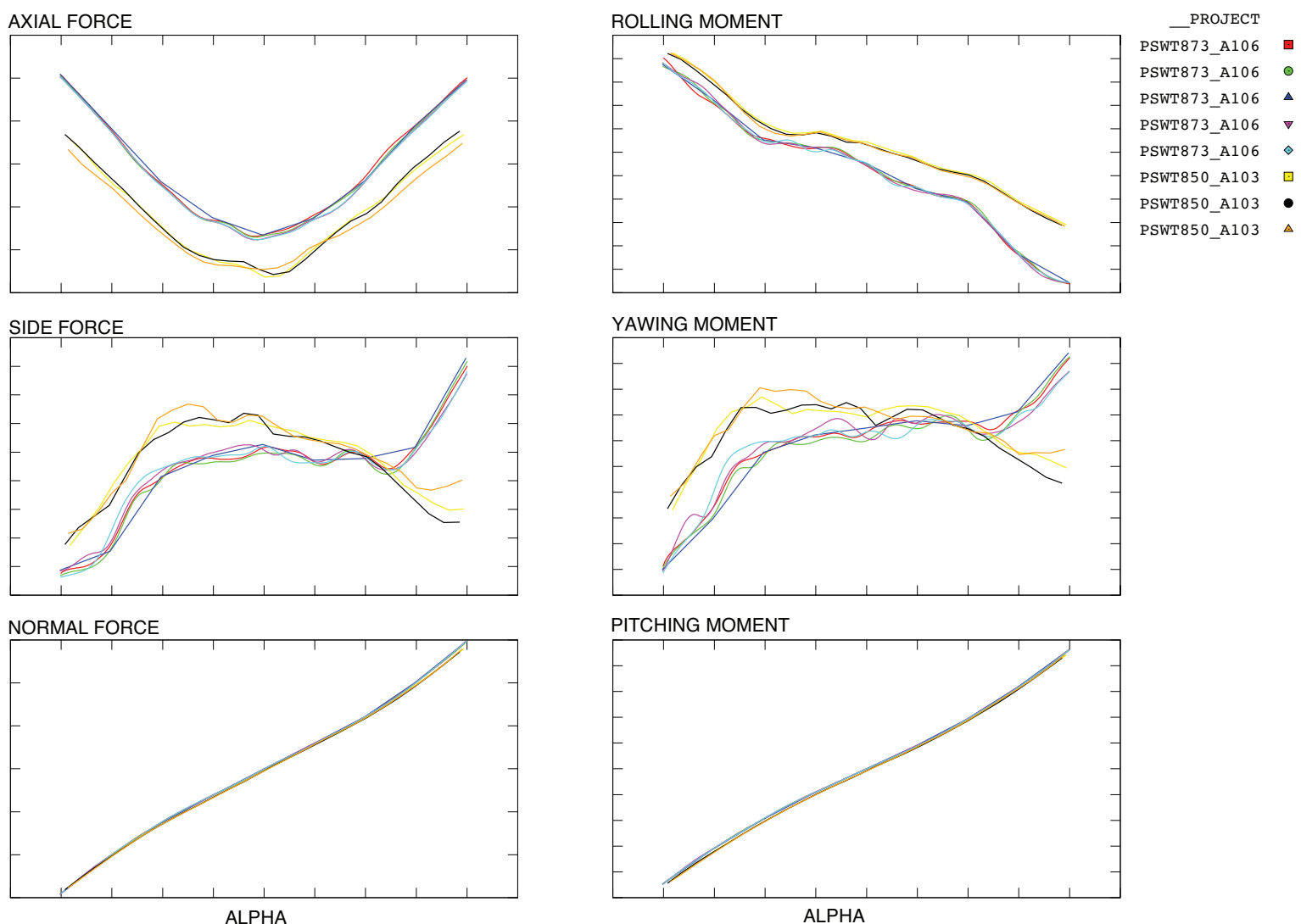

Figure 9. Comparison of Ares I A103 to A106 forces and moments during a low angle-of-attack pitch sweep at M=1.61.

Figure 9 shows a comparison of the aerodynamic trends characterizing the Ares I vehicle in its two latest configurations at a Mach number of 1.61 during a pitch sweep from $-8^{o}$ to $+8^{\circ}$ angle-of-attack. The OML differences between the A103 and the A106 configurations are small and only affect the size and position of the protuberances. The main body shape remains identical. However these small changes are showing a significant impact on axial force coefficient. In the plot, the yellow, black, and orange curves indicate the A103 configuration data from a previous test in PSWT (test 850), the others indicating A106 data from test PSWT 873. The jump in axial force is mainly due to the BDMs having been shifted back on the aft skirt, exposing them more to the incoming flow.

Figure 10 also shows that the rolling moment peaks at a much larger magnitude. The grey and red curves in these plots indicate A103 data, the others indicate A106 data. Controlling the roll rate of the vehicle experienced during flight has been a challenge throughout the design of the vehicle. Indeed the in-line first stage motor cannot impart any rolling moment on the vehicle, it therefore requires auxiliary roll control motors, the size of which needs to be minimized to maximize payload. Section C. describes the results from an attempt that was made into mitigating the aerodynamic rolling moment.

\section{Distributed loads}

Static surface pressure measurements were acquired during pressure tests as described in Section III. Using the clean axisymmetric configuration of the pressure model, roll sweeps were acquired at various angles-of-attack. By integrating the 115 static pressure measurements from the top centerline row of taps, as shown in Equation 1, a distributed 
AXIAL FORCE

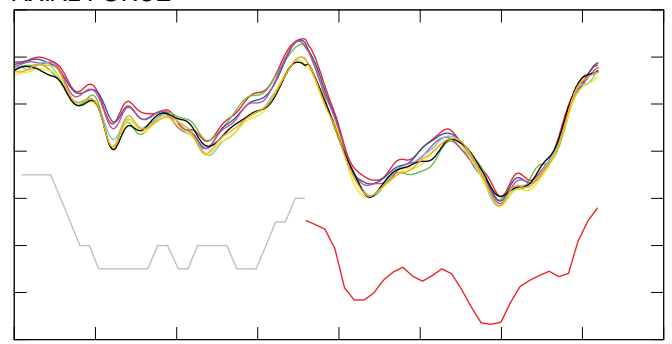

SIDE FORCE

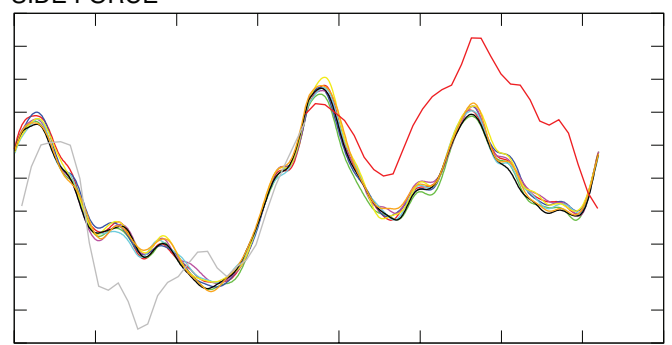

NORMAL FORCE

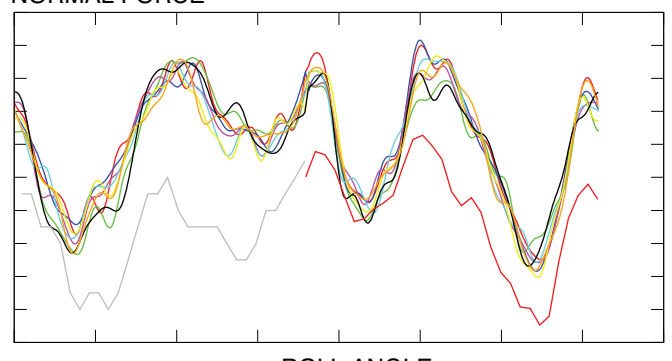

ROLLING MOMENT

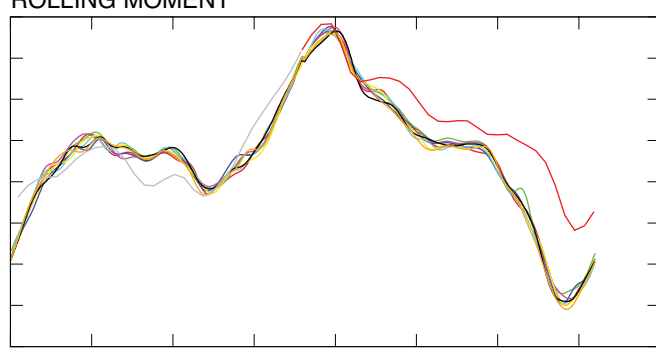

PROJECT PSWT873_A106 ם PSWT873_A106 O PSWT873_A106 \} PSWT873_A106 $\nabla$ PSWT873_A106。 PSWT873_A106 口 PSWT873_A106 • PSWT873_A106 $\triangle$ PSWT850_A103 $\nabla$ PSWT850_A103 •

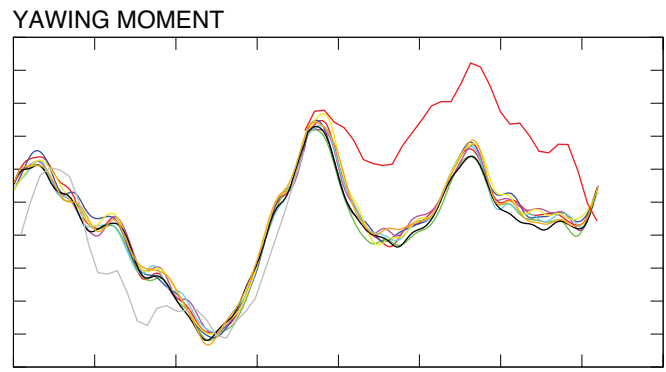

PITCHING MOMENT

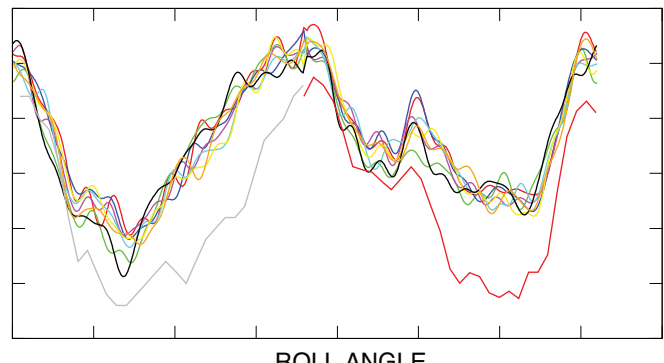

Figure 10. Comparison of Ares I A103 to A106 forces and moments during a low angle-of-attack roll sweep at M=1.61. 


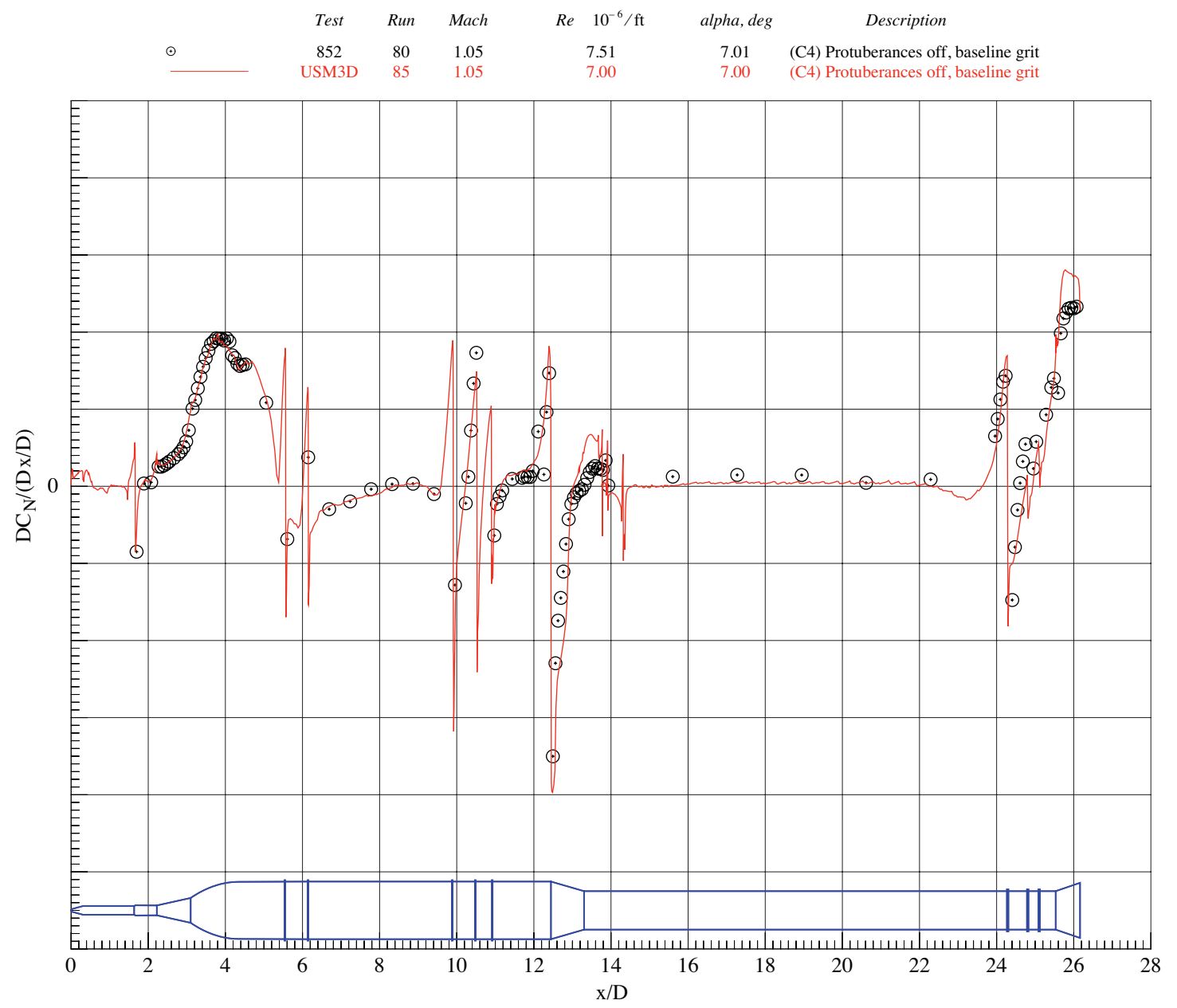

Figure 11. Normal force line-loads on the axisymmetric configuration from wind tunnel data (black dots) compared to USM3D computational simulation results (red line), $\mathrm{M}=1.05, \alpha=7^{\circ}$. 
normal force line-load is computed and displayed in Fig. 11. This data shows strong local gradients mostly associated with outer diameter changes like stiffener rings. One can also observe areas of high pressure for example at approximately mid-section of the vehicle where the diameter of the upper stage tapers down to the diameter of the first stage. This taper, called the frustum region, constitutes a backward-facing step down that is prone to flow separation at high angles-of-attack and an unfavorable pressure gradient, which explains the local drop in normal force loading. The CFD line-load (red line) computed using RANS modeling (USM3D) compares relatively well throughout the entire length of the vehicle. A more detailed description of the CFD implementation of the USM3D code with applications to Ares I can be found in Abdol-Hamid and Ghaffari ${ }^{8}$. This line-loads wind tunnel data acquired for the axisymmetric vehicle was used to validate the CFD analysis on the same geometry to justify the elaboration of a CFD-only aerodynamic line-loads database for the full-protuberance vehicle. The distributed line-loads data from wind tunnel testing was not taken with a fine enough resolution to be integrated

\section{Strake study}

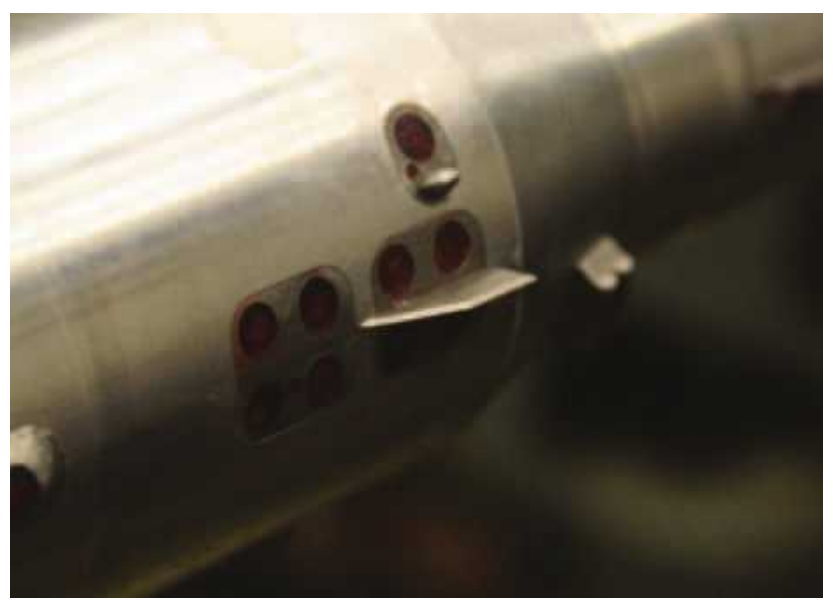

Figure 12. Picture of one of the aerodynamic strakes on the wind tunnel model utilized to mitigate rolling moment.

One of the major findings that came out of the early wind tunnel tests was that the rolling moment due to aerodynamics experienced by the vehicle, when combined to inertial rolling moments was found to exceed the control authority of the roll control system (RoCS). A strake study was therefore initiated to determine if a simple relatively small strake positioned at a beneficial location could reduce the overall aerodynamic rolling moment and alleviate some controllability issues. A preliminary CFD study reduced the size of the problem by down-selecting within a set of appropriate sizes and positions for strakes to be tested on the wind tunnel model. Two strakes of different heights and surface areas were selected as possible candidates for rolling moment mitigation. The location of the strake is on the inter-stage of the vehicle, in line with the upper-stage system tunnel. The effect of the stakes was measured in the latest PSWT test and the results are shown here.

The purpose of the aerodynamic strake is to reduce the magnitude of the maximum absolute rolling moment. At $\mathrm{M}=0.5$, the large strake (Config 5 in Fig. 13) increases the maximum rolling moment. However the small stake (Config 6) decreases the maximum rolling moment. Likewise, at $\mathrm{M}=0.9$ and 1.1 , the smaller strake provides more beneficial action than the larger one. During testing, due to time constraints, it was decided to select the smaller strake as the preferred one for testing since it was showing better results, consistent with pre-test CFD simulations. At M=1.6, the strake effect is significant and reduces by almost $50 \%$ the maximum rolling moment. This type of aerodynamic device can efficiently reduce rolling moment on vehicles with many protuberances that cannot be displaced to improve aerodynamic performance. This results in the ability to reduce the size of the auxiliary roll control motors and in turn increase the amount of allowable payload on a launch vehicle.

\section{Lessons Learned from testing at Boeing PSWT}

From the various Ares I tests performed at the PSWT wind tunnel, several issues were encountered and investigated. Some issues arose due to the type of model tested, and some were due to the facility itself and the flow conditions chosen for testing. 

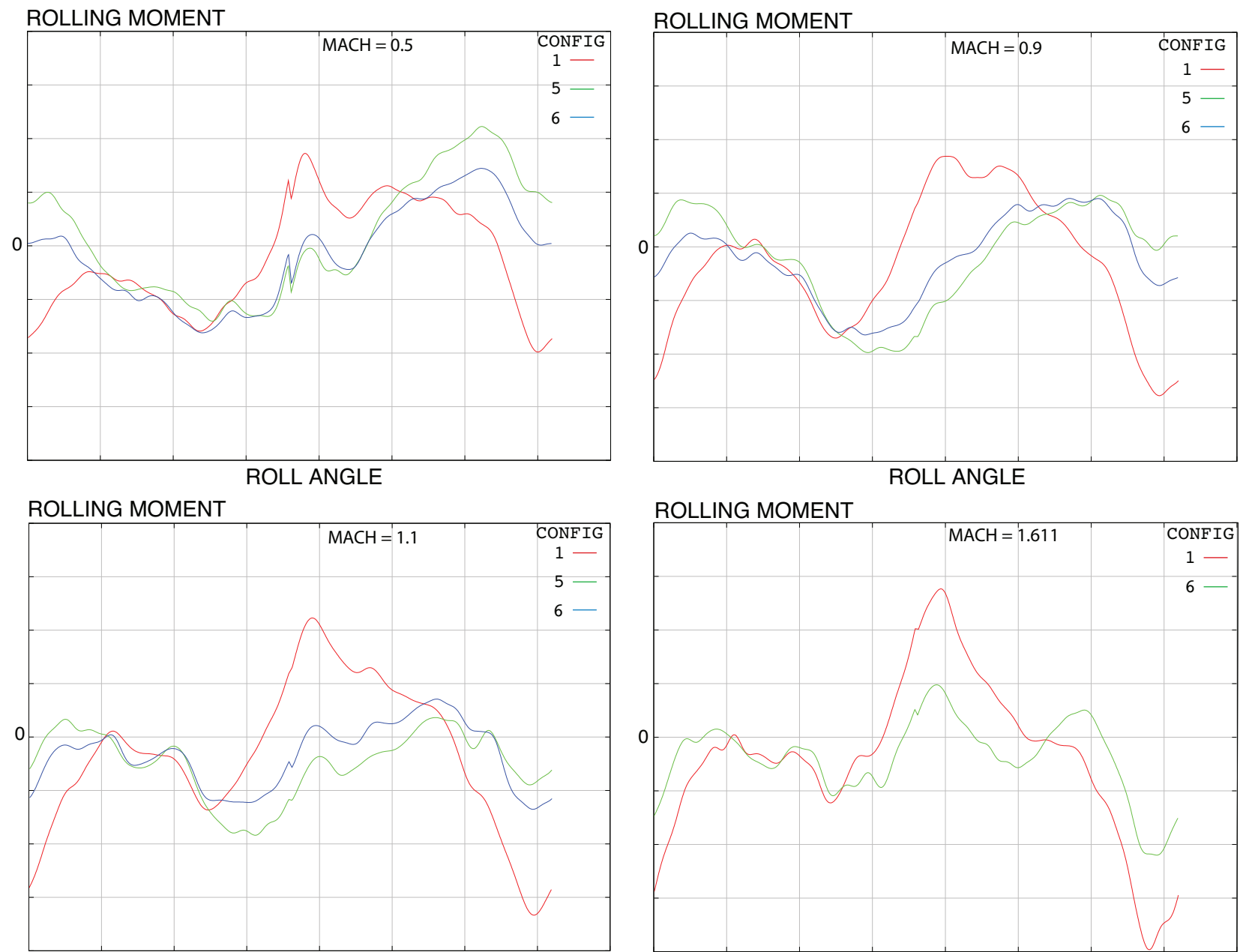

ROLL ANGLE

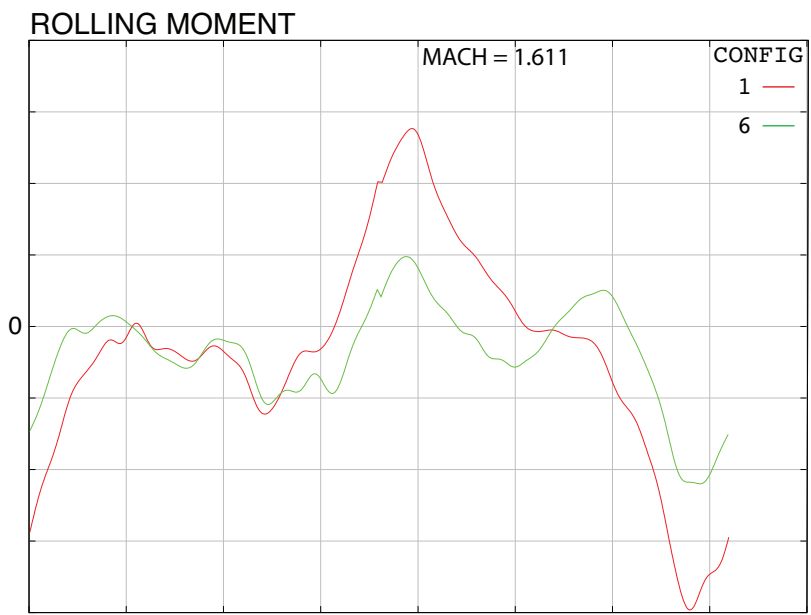

ROLL ANGLE

Figure 13. Comparison of aerodynamic rolling moment as a function of roll angle with, no strake (Config 1), a large strake (Config 5), and a small strake (Config 6) at $\mathrm{M}=0.5,0.9,1.1$ and 1.61, Alpha $=8^{\circ}$. 


\section{A. Shock reflection}

Much attention was given to the transonic part of testing ( $M=0.9$ to 1.2 ) where a conical bow shock is generated at the front of the model, reflected off the square test section walls and most likely impinges back onto the model at the centerline of the tunnel in a diffused and dissipated manner.
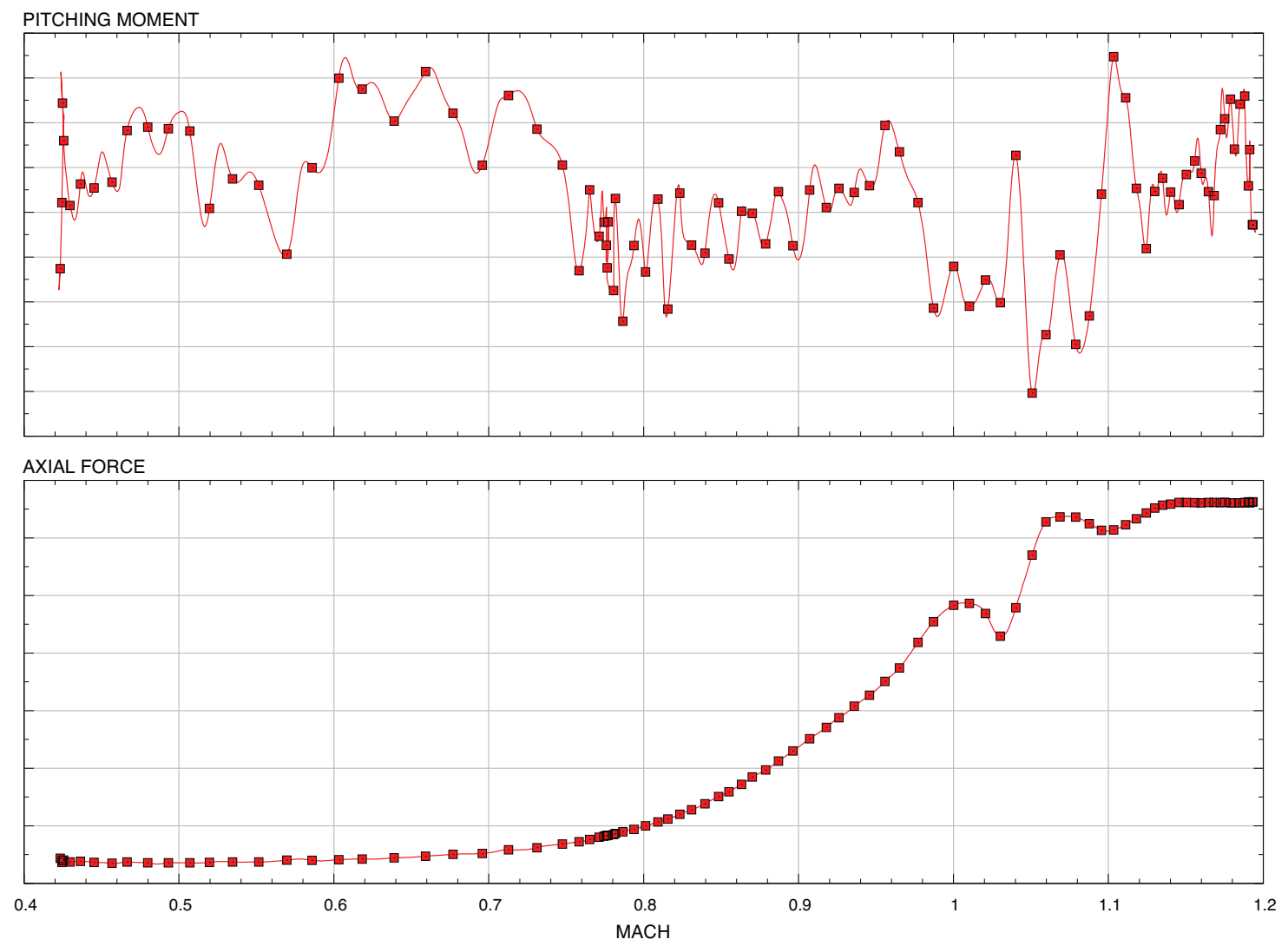

Figure 14. Pitching moment and axial force during a Mach sweep from $M=0.4$ to 1.2 at alpha $=0^{\circ}$, axisymmetric configuration.

On lifting models (e.g. aircraft) or missiles with aerodynamic fins, shock reflected data should be systematically discarded because of the large contamination expected on axial force and pitching moment coefficients. In the case of slender and axisymmetric (or missile-shaped) types of articles, the effect of reflected and diffused shocks is more subtle and difficult to measure. The main effect is usually seen on axial force. Figure 14 shows a plot of axial force as well as pitching moment during a Mach sweep performed at zero angle-of-attack with the axisymmetric configuration of the Ares I model located on the test section centerline. The two axial force dips at $\mathrm{M}=1.03$ and 1.10 are most likely indications of reflection effects. Although pitching moment seems to show an increase simultaneously with the dips in axial force, the magnitude of these increases is small, on the same order of magnitude as the variability during the entire run. Since Schlieren flow visualization is not available in the transonic test section of the tunnel it is not possible at this point to fully explain the observed reflection effects. However, the data was deemed acceptable with an added uncertainty in axial force coefficient at transonic Mach numbers. No corruption or significant effect was found in any other aerodynamic force or moment.

\section{B. Testing techniques lessons learned}

\section{Model manufacturing}

Metal rapid prototyping was used to manufacture the very small protuberances that were fastened to the aluminum model. Overall, this technique enables a much more expeditious and cost efficient fabrication process with very satisfactory finished model pieces. One of the drawbacks to this technique is that the parts are more brittle and sharp edges are subject to chipping if not treated with caution. It is not recommended to use this manufacturing technique for thin parts that could carry significant aerodynamic loads. 


\section{2. $\quad$ Pressure lag}

At the higher Mach numbers where static pressure in the tunnel is very low, significant pressure lags can be experienced in the tubing when the length from the tap to the sensor (ESP or Kulite) is greater than 2 to 3 feet. The gauge of the tubing also plays an important role, the smaller the tube diameter the larger the lag. This effect can be a problem in a blow-down facility where data is taken continuously without leaving time for the pressure to propagate along the tubes, which induces a corrupted pressure reading. During a force and moment test, if the base and cavity pressures are lagging, then the base force correction will be corrupted as well, resulting in erroneous corrected axial force coefficients. It is then extremely difficult and impractical to correct for these kinds of errors a posteriori. Therefore much care needs to be taken when designing the experiment in estimating the potential lag induced by the length of the tubing. The solution to this problem is either to slow the pitching or rolling rate during runs or to shorten the tube length by moving the sensors as close as possible to the tap location. The ideal is to have the pressure sensors inside the model, however this was not an option with the small scale and little room inside the model.

\section{Temperature gradients}

During a blow-down cycle in this tunnel, the test section temperature can vary dramatically (up to $20^{\circ} \mathrm{F}$ ), in which case if the model is small and highly heat conducive (i.e. small thermal inertia) the balance will experience significant temperature gradients across the bridge during a cycle. Strain gage balance calibrations are typically highly sensitive to temperature and such gradients could lead to biased results that vary as the temperature equalizes during the blow. It is recommended, when models are of small size to use steel rather than aluminum since steel is a lower conductor of heat. However steel being heavier other problems, including higher dynamics, could be encountered. Hard anodic coatings are also effective heat insulators for small models. It also provides a hard surface layer that prevents sand-blasting wear on forward facing surfaces.

\section{Conclusion}

Through a significant amount of wind tunnel testing at the Boeing St. Louis Polysonic Wind Tunnel, great insight into the aerodynamic characteristics of the Ares I launch vehicle was gained, in particular in the subsonic and transonic portions of flight. High fidelity databases were created from this experimental data to enable the development of the Ares I crew launch vehicle and successful qualification through its preliminary design review (PDR).

\section{Acknowledgments}

The authors would like to recognize the entire test and management personnel at the Boeing Polysonic Wind Tunnel in St Louis, MO for their efficiency and dedication during arduous testing campaigns that have provided large amounts of critical aerodynamic data to the Constellation program and in particular to the Ares I project.

\section{References}

\footnotetext{
${ }^{1}$ Erickson, G. E., "Ares I Aerodynamic Testing at the NASA Langley Unitary Plan Wind Tunnel," 49th AIAA Aerospace Sciences Meeting, Orlando, Florida, 2010.

${ }^{2}$ Hanke, J. L., "Test Summary for 1Moment Model Testing in the Boeing Polysonic Wind Tunnel, PSWT Test 850," Ares-AD-TA-0010, 2008.

${ }^{3}$ Pinier, J. T., "0.01-Scale Ares I Crew Launch Vehicle ADAC-3 (A106) Force and Moment testing at the Boeing Polysonic Wind Tunnel," Ares-AD-TA-0024, 2010.

${ }^{4}$ Erickson, G. E., "0.01-Scale CLV DAC-2A Force and Moment Model Testing in the NASA Langley Research Center Unitary Plan Wind Tunnel, UPWT Tests 1968/1813," Ares-AD-TA-0004, 2007.

5 "Calibration and Use of Internal Strain-Gage Balances with Application to Wind Tunnel Testing," AIAA Recommended Practice, AIAA R091-2003, 2003.

${ }^{6}$ Pinier, J. T., "0.01-Scale Ares I CLV ADAC-2B (A103) Pressure Model Testing from Mach 0.5 to Mach 4.4 in the Boeing Polysonic Wind Tunnel," Ares-AD-TA-0016, 2010.

${ }^{7}$ Hemsch, M. J., Hanke, J. L., and Houlden, H. P., “Quality Assurance and Uncertainty Quantification for Ares I A103 Ascent Aero Data Base,” Ares-AD-TA-0011, 2008.

${ }^{8}$ Abdol-Hamid, K. and Ghaffari, F., "An overview of Ares-I CFD Ascent Aerodynamic Data Development and Analysis based on USM3D," 49th AIAA Aerospace Sciences Meeting, Orlando, Florida, 2011.
} 